\title{
Male partners involvement in maternal ANC care: The view of women attending ANC in Hararipublic health institutions, eastern Ethiopia
}

\author{
Fekede Asefa, Ayele Geleto, Yadeta Dessie \\ Department of Public Health, College of Health and Medical sciences, Haramaya University, Ethiopia \\ Email address: \\ sinboona@gmail.com(F.Asefa), ebsature@gmail.com(A. Geleto),yad_de2005@yahoo.com (Y. Dessie)
}

\section{To cite this article:}

Fekede Asefa, Ayele Geleto, Yadeta Dessie. Male Partners Involvement in Maternal ANC Care: The View of Women Attending ANC in Hararipublic Health Institutions, Eastern Ethiopia. Science Journal of Public Health. Vol. 2, No. 3, 2014, pp. 182-188.

doi: $10.11648 /$ j.sjph.20140203.17

\begin{abstract}
Maleinvolvement in reproductive health has recently been promoted as a promising new strategy for improving maternal and child health. This is becausetheinvolvement of men in antenatal care can play a vital role in ensuring safe pregnancy, delivery and moral support to the women.However, little attention has been placed on male parnersinvolvement in maternity care in developing countries, including Ethiopia. Thus, the aim of this study was to assess male partners' involvement in maternal ANC care and identify its associated factors among pregnant women attending their ANC in Harari Regional State of Ethiopia. Institutional based cross-sectional study was conducted among 385 randomly selected ANC attendees in Harari public health institutions from February to May 2011.Data were collected using interview based questions; which was then entered into Epidata and analyzed using SPSS. Odds ratio with 95\% confidence interval was calculated to assess factors associated with male accompany at $\mathrm{p}<0.05$. The result showed that only $19.7 \%$ of the women were found to be accompanied by their spouse during their recent visit to ANC. Being a housewife $(\mathrm{AOR}=2.6,95 \%$ $\mathrm{CI} ;(1.2,5.8))$, rural residents $(\mathrm{AOR}=2.7,95 \% \mathrm{CI} ;(1.2,6.0))$ and women unsupportive of male involvement in maternal care $(\mathrm{AOR}=3.5,95 \% \mathrm{CI} ;(1.2,10))$ were more likely associated with unaccompanying male partners. The major reasons reported by women for not being accompanied by their male partnerswere: a pretext that males being preoccupied with work, lack of awareness on the possible complication during pregnancy, misconception that the ANC is the concern of women's only, males' feeling shame to accompany them on visit and lack of responsibility. In general, the involvement of male partners in maternal ANC service was found to be low in the study area. Empowering women to have open discussion with their partners about maternal health issues and creating awareness in utilizing ANC could improve male involvement in ANC in the region.
\end{abstract}

Keywords: Male Partners Accompany, ANC, Maternal Health

\section{Background}

Men and women are different in regards to their roles and responsibilities that traditional society assigns to them and their position in the family and community. These have great influences on health care seeking practice including maternal health care utilization [1]. However, as antenatal care (ANC) is a reproductive issue, it implies both men and women. Men involvement in reproductive health and their behavior imposes impact on women reproductive health, and well-being of the children and the society as well [2]. The involvement of male in reproductive health has recently been promoted as a promising new strategy to improve maternal and child health [3]. This is because men can also act as supportive caretakers and promoters of family health [4]. While, their roles in maternal health decisions are substantial, the role of male partners in other reproductive health behaviors remains largely unknown [5].

Women's lower status in the family, where decision regarding mobility and expenditure for health care are in the hands of men, may prevent them from seeking care for their own health problems [6]. Therefore, improving communication between men and women on issues of reproductive health and creating mutual understanding of their joint responsibilities is seemingly important. While, women's empowerment programs focus primarily on giving women the power of decision-making choices, male 
involvement emphasize communication and negotiation between partners in making decisions [7].

Maternal and newborn mortality remains a major public health challenge in the developing countries, and the progress made towards the achievement of millennium development goals is not satisfactory [8]. The maternal mortality ratio (MMR) in developing regions, which is 240/100,000 live birth was 15 times higher than that in developed regions. Sub-Saharan Africa had the highest MMR, at 500 maternal deaths per 100000 live births [9]. In Ethiopia, it is the case that 676 maternal death per 100,000 live birth; which is among the highest in the world [10]. In spite of this, pregnancy and child birth continue to be regarded as exclusively women's affairs in most African countries including Ethiopia. Men generally do not accompany their wives for antenatal care and are not expected to be in the labor room [11].

The ANC visit can be used as one way that healthcare providers can offer information for a pregnant woman and her family. The most important part of this follow-up is believed in making male partners involved in the ANC. However, the level to which the males involved in their partners' to antenatal is not well studied. Hence, this study was intended to investigate the level of male involvement in maternal ANC care and to identify the factors associated with ANC follow up.

\section{Methods and Materials}

This study was conducted in Harari Regional State, which is one of the nine regional states in Ethiopia. The region is found at $526 \mathrm{KM}$ away from Addis Ababa, the capital city of Ethiopia, to the East. The region has a total population of 205,000, of which the urban dwellers comprise $54.8 \%(111,052)$. The study was carried out at two public hospitals and eight health centers found in the region. It was conducted from February to May 2011.

Institutional based cross-sectional study was made among ANC attendees in the health institutions. All pregnant women who came for ANC follow up at public health institutions during the aforementioned period were the population of the study. However, the primigravidas (those with no history of previous pregnancy) and null paras (those women with no history of delivery) were purposely excluded from the study.

Sample size was calculated using open Epi version 2.3 by considering proportion of women accompanied by their husband to the ANC in Uganda $(p=0.429)$ [12], 95\%confidence interval, 5\% maximum tolerable margin of error and adding 10\% non-response rate. Thus, a sample of 415 was obtained. The sample size was proportionally allocated to each public hospitals and health centers based on the number of women attending ANC at the respective institution. Every third ANC visitor was selected by systematic sampling technique. The male partners accompanying status during the recent $\mathrm{ANC}$ visit(that we considered as an indicator of involment) wasthedependent variable. The independent variables include socio-demographic characteristics, gravidity, family size, age at first marriage and delivery, type of marriage and pregnancy intention.

The data collection was carried out using structured pretested questionnaire. The questionnaire contained closeended questions and they were developed in English language and it was translated into the local languages: Amharic and Afan Oromo. The questionnaire was developed after reviewing related literatures. The pretest was done on 20 ANC followers (roughly about 5\% of the sample size) at Haramaya Health Center, which is found outside of the study area. Based on the pretest result, some modifications were made to ensure the validity and reliability of the questions. Nurses with Bachelor Degrees were recruited for data collection and a short-term training was given for them on the study objectives and on data collection procedures.

Data collection procedures were interviewer administered. Supervisors and investigators were rechecked for completeness and coherence. The collected data was cleaned using Epidata statistical package (version 3.1).

The data were exported to SPSS version 16 statistical software for analysis. Frequencies, measure of central tendency and of dispersions estimates were used to describe variables. Male partners' accompanying on ANC visit was assessed based on the women's oral reports. Variables for which p-value is less than 0.20 by bivariate analyses were retained for subsequent multivariate analyses. Significance testing was done using odds ratio (OR) with $95 \%$ confidence intervals $(95 \% \mathrm{CI})$.

Before commencement of data collection, ethical approval was obtained from the Institutional Health Research and Ethical Review Committee (IHRERC) of the College of Health and Medical Sciences of Haramaya University. The College of Health and Medical Sciences sent an official letter to regional health Bureau and the health institutions in which the study was conducted. It was explained that the participation was voluntary; their response was confidential and they can withdraw from the study at any time without prior explanation. Accordingly, all informants were informed to obtain a written consent for giving personal information.

\section{Results}

\subsection{Socio-Demographic Characteristics of the Study}

From the 415 women sampled for the study, 385 were interviewed to give a response rate of $93 \%$. The age of respondents ranged from 15 to 49 years (mean=27.6, $\mathrm{SD} \pm 5.47$ years). As shown in table 1, the overwhelming majority, $55.8 \%$ of the respondents were in the age range of $25-35$ years. More than half, $(58.6 \%)$ of the respondents were from the rural area. Ethnically, a large number of the informants, $(60 \%)$ were Oromo; and belongs to muslin religion $(68 \%)$. More importantly, $95 \%$ of the respondents were legally married while the rest were in different 
relationships (divorce, cohabiting, and/or separated). It was possible to know that the respondents' family size was ranging from 1 to 14 .

Table 1. Socio-demographic characteristics of the respondents in Harari Regional State, Eastern Ethiopia, 2011

\begin{tabular}{|c|c|c|}
\hline Variables & Number & Percentage \\
\hline \multicolumn{3}{|l|}{ Age (in years) } \\
\hline $15-24$ years & 139 & 36.1 \\
\hline 25-34 years & 215 & 55.8 \\
\hline 35 years or above & 31 & 8.1 \\
\hline \multicolumn{3}{|l|}{ Residence } \\
\hline Urban & 159 & 41.4 \\
\hline Rural & 225 & 58.6 \\
\hline \multicolumn{3}{|l|}{ Ethnicity } \\
\hline Oromo & 230 & 59.9 \\
\hline Amara & 89 & 23.2 \\
\hline Others & 65 & 16.9 \\
\hline \multicolumn{3}{|l|}{ Religion } \\
\hline Muslim & 261 & 67.8 \\
\hline Orthodox & 102 & 26.5 \\
\hline Protestant & 22 & 5.7 \\
\hline \multicolumn{3}{|l|}{ Education } \\
\hline No formal education & 172 & 44.9 \\
\hline Primary & 130 & 33.9 \\
\hline Secondary and above & 81 & 21.2 \\
\hline \multicolumn{3}{|l|}{ Marriage } \\
\hline Legally married & 364 & 94.8 \\
\hline Other form of relationship & 20 & 5.2 \\
\hline \multicolumn{3}{|l|}{ Marriage order } \\
\hline First wife for the spouse & 350 & 91.9 \\
\hline Not first wife for the spouse & 31 & 8.1 \\
\hline \multicolumn{3}{|l|}{ Occupation } \\
\hline Employed & 78 & 20.4 \\
\hline Merchant & 49 & 12.8 \\
\hline Farmer & 58 & 15.2 \\
\hline Housewife & 175 & 45.8 \\
\hline Other & 22 & 5.8 \\
\hline \multicolumn{3}{|l|}{ Age difference } \\
\hline Five years or less & 350 & 93.3 \\
\hline Above five years & 25 & 6.7 \\
\hline
\end{tabular}

\subsection{Health Services, Obstetrical History and Marital Relationship}

As depicted in Table 2, majority of the women at marriage were between $15-20$ years. About, $42.8 \%$ have lived with their partners for about ten years and above. The respondents' gravida ranged from 1 to 12 pregnancies. One hundred forty six (i.e. $40.7 \%$ ) of the respondents had got pregnancy for about 3 to 5 times. For the majority of the participants (i.e. $44.7 \%$ ) the nearest health institution was health centers; and slightly more than half of them (i.e. $56.9 \%$ ) were travelling at most 15 minutes to access the health institutions. As illustrated in Table 3, 90 (23.4\%) of the respondents had no ANC follow up for their pregnancy before the current one. Ninety three, $(24.2 \%)$ of the respondents faced different pregnancy related problems of which vaginal bleeding, which accounts $37.8 \%$, was the leading problem. From those who faced pregnancy related problems, $18 \%$ did not seek for treatment. One hundred seventy four (i.e. $45.3 \%$ ) recently gave past birth at home and $101(26.2 \%)$ faced delivery related problems.

Table 2. Health service and obstetric history of the respondents in Harari Regional State, Eastern Ethiopia, 2011

\begin{tabular}{|c|c|c|}
\hline Variables & Number & $\%$ \\
\hline \multicolumn{3}{|l|}{ Age at first marriage } \\
\hline $10-14$ years & 21 & 5.6 \\
\hline $15-20$ years & 296 & 79.4 \\
\hline Above 20 years & 56 & 15.0 \\
\hline \multicolumn{3}{|c|}{ Length of living with spouse } \\
\hline Less than 5years & 81 & 22.5 \\
\hline $5-10$ years & 125 & 34.7 \\
\hline Above 10years & 154 & 42.8 \\
\hline \multicolumn{3}{|l|}{ Age at first birth } \\
\hline Less than 20 years & 207 & 54.3 \\
\hline $20-35$ years & 151 & 39.6 \\
\hline \multicolumn{3}{|c|}{ Number of gravida (pregnancy) } \\
\hline Less than gravida three & 145 & 37.9 \\
\hline Gravida three to five & 156 & 40.7 \\
\hline More than gravida five & 82 & 21.4 \\
\hline \multicolumn{3}{|l|}{ Nearest health institution } \\
\hline Hospital & 148 & 38.4 \\
\hline Health Center & 172 & 44.7 \\
\hline Health Post & 47 & 12.2 \\
\hline Others(different clinics) & 18 & 4.7 \\
\hline \multicolumn{3}{|c|}{ Time to reach the nearest health institution } \\
\hline 15 minutes or less & 210 & 56.9 \\
\hline $16-30$ minutes & 146 & 39.6 \\
\hline Above 30 minutes & 13 & 3.5 \\
\hline \multicolumn{3}{|c|}{ Agree on male involvement on maternal care } \\
\hline Yes & 312 & 86.7 \\
\hline No & 50 & 13.3 \\
\hline
\end{tabular}


Table 3. Recent past pregnancy and related health status of the women in Harari Regional State, Eastern Ethiopia, 2011

\begin{tabular}{|c|c|c|}
\hline Variables & Number & $\%$ \\
\hline \multicolumn{3}{|l|}{ ANC in last pregnancy } \\
\hline Yes & 295 & 76.6 \\
\hline No & 90 & 23.4 \\
\hline \multicolumn{3}{|l|}{ Male partner accompany } \\
\hline Yes & 133 & 45.2 \\
\hline No & 161 & 54.8 \\
\hline \multicolumn{3}{|c|}{ Any problems in previous pregnancy } \\
\hline Yes & 93 & 24.2 \\
\hline No & 292 & 75.8 \\
\hline \multicolumn{3}{|l|}{ Types of health problem } \\
\hline Vaginal bleeding & 34 & 37.8 \\
\hline Severe headache & 20 & 22.2 \\
\hline Sever upper epigastric pain & 2 & 2.2 \\
\hline Abnormal vaginal discharge & 8 & 8.9 \\
\hline Blurred vision & 11 & 12.2 \\
\hline Others & 15 & 16.7 \\
\hline \multicolumn{3}{|l|}{ Health measures taken } \\
\hline Taken to health institution & 64 & 71.9 \\
\hline \multicolumn{3}{|c|}{ Taken to traditional healings, including religious } \\
\hline institutions (healers) & 9 & 10.1 \\
\hline No measure was taken & 16 & 18.0 \\
\hline \multicolumn{3}{|c|}{ Place of delivery in previous pregnancy } \\
\hline At home & 174 & 45.3 \\
\hline At health institution & 210 & 54.7 \\
\hline \multicolumn{3}{|c|}{ Any health problem during the last delivery } \\
\hline Yes & 101 & 26.2 \\
\hline No & 283 & 73.5 \\
\hline \multicolumn{3}{|l|}{ Types of the problem } \\
\hline Obstructed labor & 60 & 63.2 \\
\hline Excessive vaginal bleeding & 18 & 18.9 \\
\hline Retained placenta & 6 & 6.3 \\
\hline Others & 11 & 11.6 \\
\hline \multicolumn{3}{|c|}{ Spouse involved in the health problem interventions } \\
\hline Yes & 79 & 77.5 \\
\hline No & 23 & 22.5 \\
\hline
\end{tabular}

\subsection{Characterization of Current Pregnancy and Reasons for Males Non Accompany in ANC}

As shown in table 4, while the majority, $52.6 \%$ of the women were answered thatwere never accompanied to any of their ANC visit during their recent pregnancy, only $19.7 \%$ were accompanied by their male partners during their current visit. Possible reasons why the women were not accompanied by their male partners were asked and majority of the participants $(54.6 \%)$ reported that their partners were occupied with routine jobs. In addition, $13.6 \%$ of the respondents replied that males consider the ANC is the sole responsibility of the wife/women. The data also shows that ninety six, $(30.8 \%)$ of the women's current pregnancy was unintended.

Table 4. Characterization of the current pregnancy and reasons for partners unaccompany for ANC in Harari Regional State, Eastern Ethiopia,2011

\begin{tabular}{|c|c|c|}
\hline Characteristics & No. & $\%$ \\
\hline \multicolumn{3}{|l|}{ Ever male partners accompany in the recent pregnancy } \\
\hline Yes & 148 & 47.4 \\
\hline No & 164 & 52.6 \\
\hline \multicolumn{3}{|l|}{ Pregnancy intention } \\
\hline Intended & 216 & 69.2 \\
\hline Unintended & 96 & 30.8 \\
\hline \multicolumn{3}{|l|}{ Male partners accompany in current visit } \\
\hline Yes & 76 & 19.7 \\
\hline No & 309 & 80.3 \\
\hline \multicolumn{3}{|l|}{ Reasons for not accompanying } \\
\hline Males being preoccupied with work & 210 & 54.6 \\
\hline Males believe ANC is a concern of the wife only & 52 & 13.6 \\
\hline Do not know pregnancy could result in complication & 7 & 1.8 \\
\hline Males do not feel responsible & 7 & 1.8 \\
\hline Males feel shame & 6 & 1.6 \\
\hline Women do not allow their partner to accompany & 7 & 1.8 \\
\hline They do not know the reason & 12 & 3.1 \\
\hline Other reasons & 23 & 6 \\
\hline
\end{tabular}

\subsection{Factors Related to Male Partners Unaccompany}

As shown in Table 5, in both unadjusted and adjusted analyses, occupational status of women, being a housewife were associated with high odds of malesunaccompany $(\mathrm{AOR}=2.6,95 \% \mathrm{CI} ;(1.2,5.8))$. In addition, being a rural resident increases the likelihood of males unaccompany by 2.7 times $(\mathrm{AOR}=2.7,95 \% \mathrm{CI} ;(1.2,6))$. Women who were unsupportive of males involvement on maternal care were more likely unaccompanied $(\mathrm{AOR}=3.5,95 \% \mathrm{CI} ;(1.2,10)$. A five or more years age difference between wife and their spouse was associated with higher likelihood of unaccompany in bivariate analysis while turned insignificant when adjusted for covariate $(\mathrm{COR}=2.3,95 \%$ $\mathrm{CI} ;(1.2,4.46)$ and $\mathrm{AOR}=2.2,95 \% \mathrm{CI} ;(0.9,5))$. 
Table 5. Factors associated with male partners un-accompany for ANC in Harari Regional State, Eastern Ethiopia in 2011

\begin{tabular}{|c|c|c|c|c|}
\hline \multirow{2}{*}{ Characteristics } & \multicolumn{2}{|c|}{ Unaccompany } & \multirow[t]{2}{*}{ COR (95\% CI) } & \multirow[t]{2}{*}{ AOR (95\%) } \\
\hline & Yes & No & & \\
\hline \multicolumn{5}{|c|}{ Women's occupation (310) } \\
\hline Employed & $27(16.6)$ & $40(27.20)$ & 1 & 1 \\
\hline Merchant & $23(14.1)$ & $20(13.6)$ & $1.7[0.78-3.7]$ & $0.72[0.27-1.9]$ \\
\hline Farmer & $20(12.3)$ & $31(21.1)$ & $0.96[0.45-2.01]$ & $0.9[0.27-3.1]$ \\
\hline Housewife & $84(51.5)$ & $46(31.3)$ & $2.7[1.47-4.96] *$ & $2.6[1.2-5.8] *$ \\
\hline Others $* * * *$ & $9(5.5)$ & $109(6.8)$ & $1.33[0.48-3.7]$ & $1.5[0.43-5.5]$ \\
\hline \multicolumn{5}{|c|}{ Women's ethnic group (311) } \\
\hline Oromo & $86(52.4)$ & $94(63.9)$ & 1 & 1 \\
\hline Amhara & $44(26.8)$ & $34(23.1)$ & $1.4[0.83-2.4]$ & $2.4[0.8-7]$ \\
\hline Others** & $34(20.7)$ & $19(12.9)$ & $1.96[1.04-3.7] *$ & $2.5[1.1-5.8] *$ \\
\hline \multicolumn{5}{|c|}{ Women's religion (312) } \\
\hline Muslim & $108(65.9)$ & 99 (66.9) & 1 & 1 \\
\hline Orthodox & $51(31.1)$ & $35(23.6)$ & $1.34[0.8-2.2]$ & $3.9[1.1-15] *$ \\
\hline Protestant & $5(3)$ & $14(9.5)$ & $0.33[0.12-0.94]$ & $3.4[0.9-13]$ \\
\hline \multicolumn{5}{|l|}{ Residence (311) } \\
\hline Urban & $62(37.8)$ & $63(42.9)$ & 1 & 1 \\
\hline Rural & $102(62.2)$ & $84(57.1)$ & $1.23[0.78-1.9]$ & $2.7[1.2-6] *$ \\
\hline \multicolumn{5}{|c|}{ Agreeing on male involvement on maternal care (308) } \\
\hline Yes & $129(79.6)$ & $138(94.5)$ & 1 & 1 \\
\hline No & $33(20.4)$ & $8(5.5)$ & $4.4[2-9] *$ & $3.5[1.2-10] *$ \\
\hline \multicolumn{5}{|c|}{ Age difference with spouse (310) } \\
\hline 5 years or less & $129(79.1)$ & $132(89.8)$ & 1 & 1 \\
\hline Above 5 years & $34(20.9)$ & $15(10.2)$ & $2.3[1.2-4.46] *$ & $2.2[0.9-5]$ \\
\hline \multicolumn{5}{|l|}{ Parity (296) } \\
\hline $1-3$ & $65(41.1)$ & $84(60.9)$ & 1 & 1 \\
\hline $4-6$ & $56(35.4)$ & $42(30.4)$ & $1.7[1.03-2.9]^{*}$ & $1.5[0.8-2.9]$ \\
\hline Above 6 & $37(23.4)$ & $12(8.7)$ & $3.9[1.9-8.2]^{*}$ & $7.2[2.3-22]^{*}$ \\
\hline \multicolumn{5}{|c|}{ Time gap between current and previous pregnancy (293) } \\
\hline Less than 2 years & $12(7.6)$ & $25(18.5)$ & 1 & 1 \\
\hline 2-3years & $115(72.8)$ & $80(59.3)$ & $3[1.4-6.3] *$ & $8.7[2.9-25] *$ \\
\hline Above 3years & $31(19.6)$ & $30(22.2)$ & $2.2[0.9-5] *$ & $3.5[1.1-11.3] *$ \\
\hline \multicolumn{5}{|c|}{ Previous pregnancy ANC follows up (312) } \\
\hline Yes & $123(75)$ & $127(85.8)$ & 1 & 1 \\
\hline No & $41(25)$ & $21(14.2)$ & $2[1.13-3.6] *$ & $4.2[1.6-11] *$ \\
\hline \multicolumn{5}{|c|}{ Discussion about pregnancy Problem (309) } \\
\hline With spouse & $110(67.5)$ & $125(85.6)$ & 1 & 1 \\
\hline With others*** & $11(6.7)$ & $13(8.9)$ & $0.96[0.4-2.2]$ & $2.3[0.67-8.1]$ \\
\hline With nobody & $42(25.8)$ & $8(5.5)$ & $5.9[2.7-13] *$ & $3.6[1.3-10] *$ \\
\hline \multicolumn{5}{|c|}{ Pregnancy intention (312) } \\
\hline Intended & $95(57.9)$ & $121(81.8)$ & 1 & 1 \\
\hline Unintended & $69(42.1)$ & $27(18.2)$ & $3.25[1.9-5.4] *$ & $1.3[0.6-2.8]$ \\
\hline
\end{tabular}

*significant association $\quad * *$ Gurage, Harari, Somale $\quad * * *$ relative, friends, mother-in-law $\quad * * *$ daily labor, no work

\section{Discussions}

The result in this study shows that high proportion of the women was not accompanied by their male partners. Moreover, being a rural resident, lack of discussion about the possible pregnancy problem with their male partners, lack of ANCfollowup for the last pregnancy,being above para six and women's disagreement on the importance of male involvement in maternal health increases the likelihood of male partners to unaccompany them on ANC visit.

Study conducted in Nepal showed that about $40 \%$ of male partners accompanying their partner at ANC follow up [13]. Similarly, a study conducted in Uganda revealed that $42.7 \%$ of males accompanied their partner for ANC [14]. A study from India, however indicates that only $18.33 \%$ of male partners were reported to present during antenatal checkups [15]. Similar to this, but more surprisingly, the finding in this study also shows that $52.6 \%$ of the women were never accompanied to any of their ANC visit and only $19.7 \%$ were accompanied by their male partners during their current visit. The reason why they were not accompanied to the visit were identified to be a pretext of being preoccupied with work, lack of knowledge that pregnancy could result in different complications, a belief that the ANC is the issue of women's only, male's feeling shame to accompany and lack of responsible. The findings of this study is consistent with other studies' in revealing similar reasons for males not to accompany their female partners during ANC visit [13, 15-18].

It was possible to identify in this study that significant numbers of current pregnancies are unintended. The odds of partners who were not accompanied in their ANCvisit was higher for unintended pregnancy than the intended 
ones. If the pregnancy is unintended, it leads even to lower utilization of ANC. In supporting this, studies also show that women who wanted their pregnancy are 1.5 time more likely to have used prenatal care than wanted pregnancy [19] and the risk of delaying ANC initiation is higher for unwanted pregnancy than intended pregnancies [20]. Accordingly, lower interest of husband for unintended pregnancy and poor communication of couple about this unintended pregnancy could explain the un-accompany.

With regard to women's having discussion about health issues during pregnancy with their male partners, about $76 \%$ of women were reported to do so; this is very similar to a study done in Nepal, which is $75 \%$ of women reported to discuss with their spouse[21]. Furthermore, it was also identified that intra-spousal communication about maternal health issue is associated with higher odds of males accompany, which is similar to the result reported from a study conducted in India [22]. Thus, the poor communication system among couples, could result in males lack of involvement [14]. This might also be due to the fact that communication and/or interaction between couples regarding health practices lead to a greater understanding of their joint responsibilities in maternal health.

This result showed that the majority, (i.e. 86.7\%) of women wanted their partners' participation; while only $13.3 \%$ were not in support of their male partners' involvement in maternal care. This result is similar to a study conducted in Cameroon, which noted that only $12 \%$ of the women do not support their partner's involvement in maternal care [23]. In our study, women who were not supporting their partners to involve in maternal care were 3.5 times more likely to be unaccompanied by their spouse. This might be due to gender norms where inhibit males' involvement in maternal health care and men are not expected culturally to accompany their wives to the ANC visit. Moreover, there might be a fear that other people may consider a male partner as female if he is seen at ANC clinic.

Women's age is not appeared to be significantly associated with males accompany at ANC visit in this study. In contrast to our study, studies from Nepal and India noted older aged women weremore likely to be accompanied by their spouses[13, 24]. There were contradictory findings regarding the educational status of males and accompanying their partners. Some findings indicate that attending no education or primary education increased the likelihood of male accompany [13]; while others reported that attending secondary or more education associated with increased odds of accompany[14, 24]. In our study, however, educational status was not observed to be predictors of males' accompany. Similarly, males' occupational status was also not found to be associated with accompanying spouses at the ANC visit. On the other hand, females' occupational status was identified as a factor associated with male partners escorting during ANC visit. Hence, a housewife is less likely to be accompanied by her male partner during an $\mathrm{ANC}$ visit.

Women who have ANC follow-up for the latest pregnancy are less likely to be unaccompanied. One study from southern Ethiopia reported that women who had used prenatal care during a prior pregnancy were 50 percent more likely to use prenatal care during the most recent pregnancy than women with no prior prenatal care experience [19]. This could be due to the fact that they have a previous ANC follow-up increase awareness of females on the importance of male involvement in maternal care.

This study has some limitations. Firstly, since it is a crosssectional study, it is more likely to prone to social desirability bias. In addition, it was conducted only on ANC attendants so that it may not represent all women in the region.

\section{Conclusions}

The involvement of male partners in the maternal ANC service is low in the Harari Regional State. Moreover, being a rural resident, lack of discussion about the possible pregnancy problem with their male partners, lack of ANC followup for the last pregnancyand women's disagreement on the importance of male involvement in maternal health increases the likelihood of male partners to unaccompanythemon ANC visit.

\section{Recommendations}

1. The concerned bodies should empower women to have open discussion with their partners about maternal health issue.

2. Educating women to utilize the ANC could improve male involvement in maternal care.

3. Health providers and other stakeholders need to focus on educating men on their shared responsibility in ANC.

\section{Abbreviations}

ANC: Antenatal Care

AOR: Adjusted Odds Ratio

CI: Confidence Interval

COR: Crude Odds Ratio

ICPD: International Conference on Population and Development

IHRERC: Institutional Health Research and Ethical Review Committee

MDG: Millennium Development Goals

MMR: Maternal Mortality Ratio

SPSS: Statistical Package for Social Science

\section{Competing Interests}

The authors would like to declare that they have no any competing interest.

\section{Authors' Contributions}

FA has carried out the overall design and execution of 
the study, performed data collection, statistical analysis and drafted the manuscript. AG has also carried out the overall design and execution of the study, performed data collection and has critically revised the manuscript. YD has conceived the study, critically revised the design of the study, data collection techniques and helped the statistical analysis. All authors read this manuscript and finally approved for submission.

\section{Acknowledgment}

The authors would like to warmly acknowledge Haramaya University for funding the research. Next, we would like to thank data collectors and study participants. Last but not least, our thanks go to those individuals who directly or indirectly contributed their skills and knowledge toward the accomplishment of this study.

\section{References}

[1] Ostllin P, Eckiman E, Mashra US, Nkowne M, Wallstam E: General health promotion: a multisectoral policy approach. Health promotion international 2007, 21(1).

[2] Reproductive Health Promotion Working Group (RHPWG): Male involvement is key to reproductive health MEDiCAM; 2004.

[3] UNFPA, Cohen SI, Burger M: Partnering: a new approach to sexual and reproductive health In Technical Paper Volume 3. UNFPA; 2000.

[4] Carter M: Husbands and maternal health matters in rural Guatemala: wives' reports on their spouses' involvement in pregnancy and birth. Social Science \& Medicine 2002, 55(3):437-450.

[5] Dudgeon MR, Inhorn MC: Men's influence on women's reproductive health: medical anthropological perspectives. Social Science \& Medicine 2004 59:1379-1395.

[6] Porter M, SinkhadaB, VanTeinjlinger ER, Simkhada P: Major problems and key issues in maternal health in Nepal. Kathmandu University medical journal 2006, 18(2):258-263.

[7] UNFPA: Investing in people: National progress in implementing the ICPD Program of Action 1994-2004. In Special Report. UNFPA; 2004.

[8] WHO, UNICEF, UNFPA, World Bank: Trends in maternal mortality: 1990 to 2010 WHO, UNICEF, UNFPA and The World Bank estimates. Geneva: World Health Organization; 2012 .

[9] United Nations (UN): The Millennium Development Goals Report. New York: United Nations; 2013.

[10] Central Statistical Agency: Ethiopia Demographic and Health Survey. Addis Ababa, Ethiopia Central Statistical Agency; 2011
[11] Mullick S, Kunene B, Wanjiru M: Involving men in maternity care: health service delivery issues. Agenda Special Focus 2005:124-135.

[12] Kakaire T, Kaye DK, Osinde MO: Male involvement in birth preparedness and complication readiness for emergency obstetric referrals in rural Uganda. Reproductive Health 2011, 8(12): 1-7.

[13] Bhatta DN: Involvement of males in antenatal care, birth preparedness, exclusive breast feeding and immunizations for children in Kathmandu, Nepal. BMC Pregnancy and Childbirth; 2013, 13(14):1-7.

[14] Nantamu DP: Factors associated with male involvement in maternal health care services in jinja district, uganda. Makerereuniversity, school of public health; 2011.

[15] Awasthi S, Nandan D, A.K. Mehrotra, Shankar R: Male participation in maternal care in urban slums of district agra. Indian J PrevSoc Med 2008, 39 (3\& 4):181-183.

[16] Lucy IK, Johanne S, Ellen C, Address M, Alfred M: Barriers to husbands' involvement in maternal health care in a rural setting in Malawi: a qualitative study. Journal of Research in Nursing and Midwifery; 2012, 1(1):1-10.

[17] Godlove N. Nkuoh, Dorothy J. Meyer, Joseph N: Barriers to Men's Participation in Antenatal and Prevention of Motherto-Child HIV Transmission Care in Cameroon, Africa. Journal of Midwifery \& Women's Health 2010, 55(4):363369.

[18] Kwambai TK, Dellicour S, Desai M, Ameh CA, Person B, Achieng F, Mason L, Laserson KF, Kuile FO: Perspectives of men on antenatal and delivery care service utilisation in rural western Kenya: a qualitative study. BMC Pregnancy and Childbirth 2013, 13(134):1-10.

[19] Biratu BT, Lindstrom DP: The influence of husbands' approval on women's use of prenatal care: Results from Yirgalem and Jimma towns, south west Ethiopia EthiopJHealthDev 2006, 20(2):84-92.

[20] Exavery A, KantéAM, HingoraA, Mbaruku G, Pemba S, Phillips JF: How mistimed and unwanted pregnancies affect timing of antenatal care initiation in three districts in Tanzania. BMC Pregnancy and Childbirth 2013, 13(35):1-11.

[21] Mullany BC, Hindin MJ, Becker S: Women's autonomy and male involvement in antenatal care in Napal: associations and tensions. John Hopkins Bloomberg School of public Health Baltimore USA 2004.

[22] Thapa DK, Niehof A: Women's autonomy and husbands' involvement in maternal health care in Nepal. Social Science \& Medicine 2013, 93: 1-10.

[23] Nkuoh GN, Meyer DJ, Nshom EM: Women's Attitudes Toward Their Partners' Involvementin Antenatal Care and Prevention of Mother-to-Child Transmission of HIV in Cameroon, Africa. Journal of Midwifery \& Women's Health 2013, 58(1):83-91.

[24] Kumar P, Singh SK: Does Male Participation in Maternal Health can ensure achieving MDGs in India? Evidences from National Family Health Surveys. 